\title{
Pitheciid vocal communication: what can we say about what they are saying?
}

Bruna Bezerra ${ }^{1,7^{*}}$, Cristiane Cäsar 2,3 , Leandro Jerusalinsky4, Adrian Barnett ${ }^{5,6}$, Monique Bastos ${ }^{1}$, Antonio Souto ${ }^{1}$, Gareth Jones ${ }^{7}$

\begin{abstract}
The variation in ecological traits in pitheciids allow investigation of vocal communication across a range of social and acoustic circumstances. In this review, we present a summary of the history of pitheciid vocal studies, and review i) the status of current knowledge of pitheciid vocal repertoire sizes, ii) how much we understand about the context of different acoustic signals, and iii) how can we potentially use our knowledge of vocalizations in animal welfare practices. The repertoires described for titi monkeys and sakis have the expected sizes for these genera, considering their relatively small social group sizes. However, uacari groups can contain over 100 individuals, and a larger vocal repertoire than the ones described would be expected, which could be a consequence of the fission-fusion social system where the large group divides into smaller subgroups. Nevertheless, vocal repertoires exist for only about $12 \%$ of the pitheciid species and nothing is known, for example, concerning call ontogeny. We hope that this study will act as a reference point for researchers interested in investigating vocal behaviour in pitheciids, thus, optimising both funding focus and, researcher's time and effort. Also, we hope to help defining methodologies and strategies for the conservation and management of pitheciid monkeys.
\end{abstract}

Keywords: Vocal Repertoires; Meaning Attributed Calls; Alarm Calls; Conservation Methods; Playback Survey; Welfare Practices.

\footnotetext{
1 Universidade Federal de Pernambuco, Centro de Biociências, Pernambuco, Brazil.

${ }^{2}$ Museu de Ciências Naturais, Pontifícia Universidade Católica de Minas Gerais, Brazil.

${ }^{3}$ Bicho do Mato Instituto de Pesquisa, Brazil.

4 Centro Nacional de Pesquisa e Conservação de Primatas Brasileiros - Instituto Chico Mendes de Conservação da Biodiversidade, Brazil.

${ }^{5}$ Centre for Research in Evolutionary and Ecological Anthropology, Department of Life Sciences, University of Roehampton, London, England, UK.

${ }^{6}$ Grupo de Pesquisa de Mamíferos Amazônicos, Coordenação de Biodiversidade, Instituto Nacional de Pesquisas da Amazônia, Manaus, Amazonas, Brazil.

${ }^{7}$ University of Bristol, School of Biological Sciences, Bristol, United Kingdom.
} 


\section{INTRODUCTION}

For animals living in densely vegetated habitats, the use of vocal communication has advantages as vocal signals can propagate over longer distances than visual signals. Thus, vocalizations in such habitats can optimize communication, balancing costs and benefits to both sender and receiver. Several information elements can be encoded in a single acoustic signal, ranging from species to body size, caller distance, gender, age, predation threats and the animal's inner state (Bradbury and Verrencamp 2011; Ey and Ficher et al. 2009; Wheeler and Fischer 2015).

It has been suggested that information encoded in vocalizations can help to maintain group structure, cohesion and survival, and may reveal patterns in habitat use and social organization between primate species (e.g. Brown and Waser 1988; Fitchel and Manser 2010; Maciej et al. 2013; Fischer and Price 2016). Since vocal communication is a biological process and requires adaptations from both caller and receiver, evolution had played a key role in structuring of the currently operating forms (Bradbury and Verrencamp 2011; Kroodsma and Miller 1996). Furthermore, vocal communication strongly shapes animal behaviours, influencing anti-predation strategies, mating and even such food gathering systems as cooperative foraging (Ey and Ficher et al. 2009; Semple and Higham 2013).

All living Pitheciidae are social and arboreal. The family comprises the subfamilies Callicebinae, where the titi monkey genus, Callicebus, was recently split into the genera Callicebus, Cheracebus, and Plecturocebus species [Byrne et al. 2016]), and the Pitheciinae (Pithecia, Chiropotes and Cacajao) (Groves 2001; 2005). There are currently 34 titi monkeys species, 16 Pithecia species (sakis), five Chiropotes species (cuxius) and six Cacajao taxa (uacaris) described (Byrne et al. 2016; Vermeer and Tello-Alvararado 2015, Marsh 2014; Dalponte et al. 2014; Silva-Junior et al. 2013). Pitheciids show considerable variation in social traits and range sizes - for example, while all titi monkeys and many sakis form small groups in small territories, groups of uacaris and cuxius in some areas can be very large and range over extensive areas (Barnett et al. 2005; Bowler et al. 2012; Defler 2003; Dixson and Anderson 2001; Fontaine 1981; Norconk 2006, 2007; Pinto 2008; Silva and Ferrari 2009; SouzaAlves and Ferrari 2010; Veiga 2006). This variation in social traits and range sizes in pitheciids allows investigations of the vocal communication in this primate family that cover a wide range of social and acoustic circumstances. The use of vocalizations for communication is important for pitheciid primates due to the restricted visibility of their structurally complex and dense natural habitats (Bezerra et al. 2011a,b).

Here we present a history of pitheciid vocal studies, and consider the following questions: 1) What is the current state of knowledge of the vocal repertoire sizes of pitheciid primates? 2) How much do we understand about the context and functional significance of different signals? and 3) How can we use the current knowledge to animal welfare, especially for captive animals? The answers provided are based on a review of the literature that aims to synthesize published information on the vocal communication of pitheciids. In our online literature search, we used the terms "(genus) bioacoustics", "(genus) vocal communication", "pitheciid communication", "(genus) vocal repertoires", "(genus) calls", "(genus) vocalization" to search for 
information on acoustic communication in pitheciids. These terms could be either in the tittle or main of text of the study. To our knowledge no papers on titi monkey vocalizations have yet published using the new nomenclature of Byrne et al. (2016), but for convenience we will use the phrase "titi monkeys" when referring to Callicebus, Cheracebus and Plecturocebus collectively in this paper. Also, for convenience, we will be referring to Cacajao as "uacaris", Pithecia as "sakis", and Chiropotes as "cuxius". We searched the following databases: Google Scholar, Web of Science, PrimatLit, PubMed and Periódicos CAPES. We also considered books that are not available online and articles that were not available in electronic format. In the Google Scholar database, all articles included in the first 20 Google pages (up to 200) were inspected for information on pitheciid acoustic communication. We included only studies that focused on pitheciids, and excluded those that only mentioned any of the pitheciid species as part of their discussion or introduction. In the current review, we only focused on vocal communication and excluded non-vocal acoustic signals, such as noises made by shaking or breaking branches. We hope this study will serve as a reference for researchers aiming to identify gaps in the knowledge of vocal behaviour in this primate group and define effective methodologies (e.g. playback and automated call surveys in isolated areas) and strategies for the conservation (e.g. Sobroza et al. 2017) of pitheciid monkeys. Many pitheciid species face threats to their survival (IUCN 2017). However, studies on both threatened and non-threatened species are needed to help prevent the latter also attaining threatened status. For both threatened and nonthreatened pitheciid species, focusing research on knowledge gaps may help optimize funding, researchers' effort and time, and contribute most effectively to the conservation of these primates.

Note: the text follows Ferrari et al. (2014) in using Cacajao ouakary for black-headed taxa south and west of the Rio Negro and Cacajao melanocephalus for those to the north and east of this river. We also follow Silva-Junior et al. (2013), Marsh (2014) and Byrne et al. (2016) for the taxonomy of cuxius, sakis and titi monkeys, respectively.

\section{What is the current knowledge of the vocal repertoires sizes of pitheciid primates?}

A total of 78 studies were related to vocal communication in the genera titi, sakis, cuxius and uacaris (Electronic Supplementary Material 1). Researchers have encountered a variety of difficulties when investigating pitheciids in the wild, many related to the challenging nature of their natural habitats, expensive fieldwork logistics, and an often protracted habituation process (e.g. Souza-Alves and Ferrari 2010; Pinto et al. 2013). Despite these issues, there have been significant advances in our knowledge of these monkeys in recent years (e.g. Veiga et al. 2013; Barnet et al. 2016). The studies on pitheciid vocal communication began in the 1960's with titi monkeys, but most studies have been conducted in the last two decades. Over this period, equipment became steadily more portable and efficient, making it easier to conduct recordings of wild primates (Bezerra et al. 2011a,b).

The size of the vocal repertoire varies from 9-12 call types in uacari species ( $C$. ouakary: Bezerra et al. 2010a; C. calvus: Fontaine 1981), 12-13 call types in saki species (vocal repertoires described for $P$. pithecia: Buchanan et al. 1981; Henline 
2007; and P. irrorata: Adams and Erhart 2009) and 6-13 call types in titi monkey species (vocal repertoires described for three species: Plecturocebus moloch (formerly Callicebus moloch: Moynihan 1966; Robinson 1979; Cheracebus torquatus (formerly Callicebus torquatus): Kinzey et al. 1977; Callicebus nigrifrons: Cäsar 2011; Cäsar et al. 2012a). There are no quantitative analyses of full vocal repertoires of cuxius, though van Roosmalen et al. (1981) provide onomatopoeic descriptions of three calls for Chiropotes satanas. In total some $12 \%$ of pitheciid taxa have had their vocal repertoires described.

\section{How much do we understand about the context of different signals?}

\section{Call features}

Call structure (e.g., duration and frequency) can often reveal information about the caller (Bradbury and Vehrencamp 2011). This is true in pitheciines: in uacari species, for example, such structure provide clues about the behavioural context and identity of the caller (Fontaine 1981; Bezerra et al. 2010a,b). For Cacajao ouakary, the structure of the tchó call (Figure 1) varies between individuals, indicating a potential for individual identification and monitoring in the wild (Bezerra et al. 2010a). Additionally, the structure of this call varied according to the behavioural context under which it was produced (i.e. foraging, traveling or agonistic interactions). When uttered in agonistic situations, tchó calls were on average shorter in duration and had higher frequencies than when emitted under foraging and travelling contexts (Bezerra et al. 2010b). It should be harder to locate a caller when it emits shorter calls than when it produces longer calls (Skowronski and
Fenton 2009), as short high pitch signals are more easily dispersed in closed habitats when compared to longer lower pitch signals (Ey and Fischer 2009). Thus, in such circumstances, $C$. ouakary could be trying to avoid being located and engage in costly agonistic physical contacts, but still transmit information, by emitting shorter and higher pitch tchó calls in agonistic contexts. In terms of fighting strategy models (Bradbury and Vehrencamp 2011), this could be a tactic to help in conflict resolution with the lowest possible risk to the signaller. Predator avoidance is also a possibility as the species is known to be taken by harpy eagles (Barnett et al. 2011), a species known to use auditory as well as visual cues when locating prey (Gil-da-Costa 2007). Differences in call structure associated to different behavioural contexts could also be due to variations in the animal's inner state (Hewson 2004; Linhart et al. 2015). There is some evidence that tchó calls may be adapted for effective propagation in flooded forests, suggesting that the call could be related to group/territorial defence (Bezerra et al. 2010b; 2012). Similarly, some saki calls may be involved in both territorial defence and in providing information on a signaller's location (e.g. Di Fiore et al. 2007; Fernandez-Duque et al. 2013). Further studies are required to ascertain the meaning of the uacari and saki calls based on their structure and the signal receiver's perspective.

\section{Call contexts}

Saki species have, at least, three loud calls that could possibly be related to group coordination and defence of resources (Henline 2007). Uacari species have context- and age-specific calls as well as calls uttered in a range of different 


\section{Call A - chirps - Callicebus}

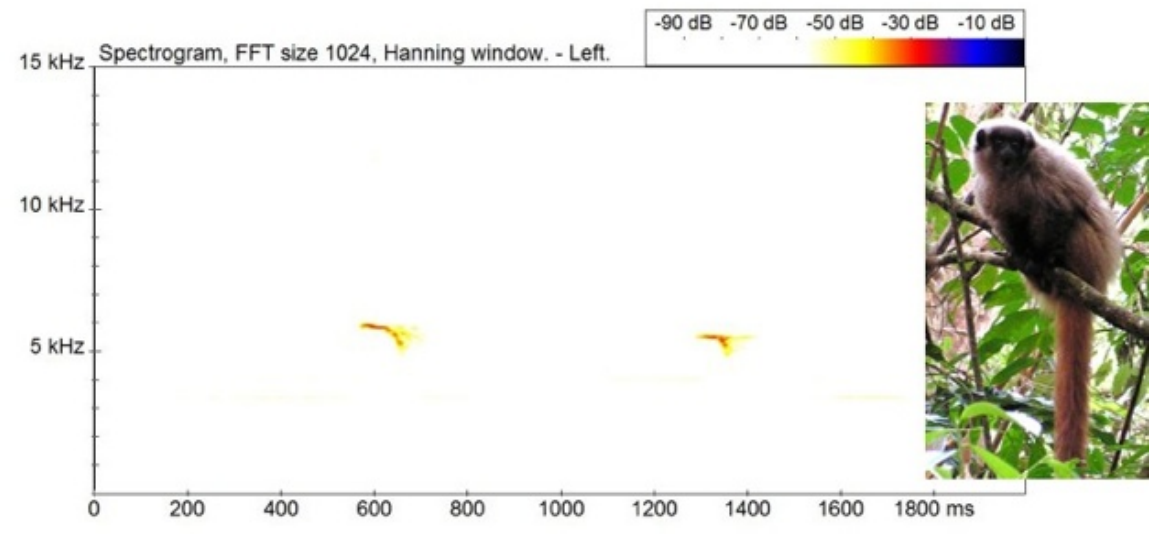

\section{Call B - cheeps - Callicebus}

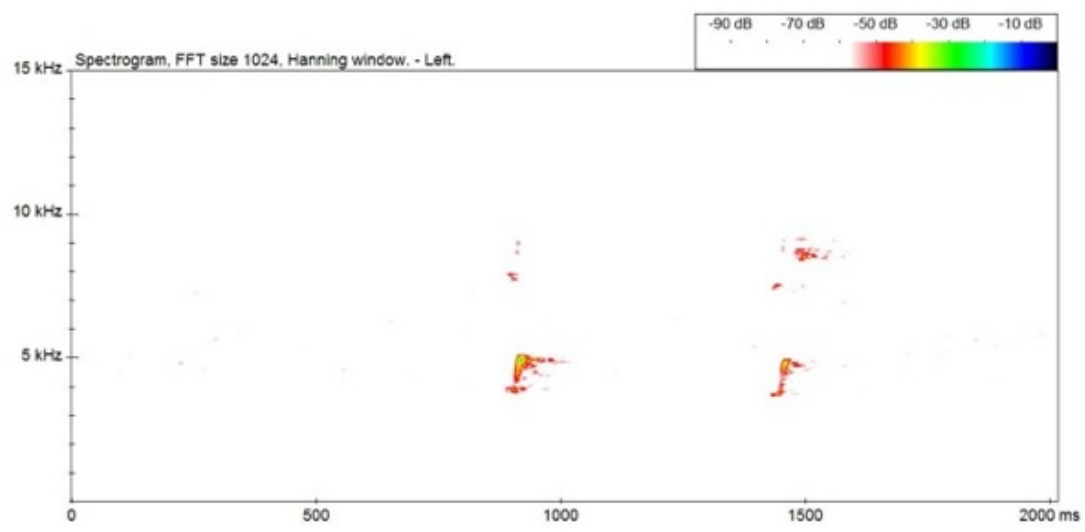

\section{Tchó call - Cacajao}

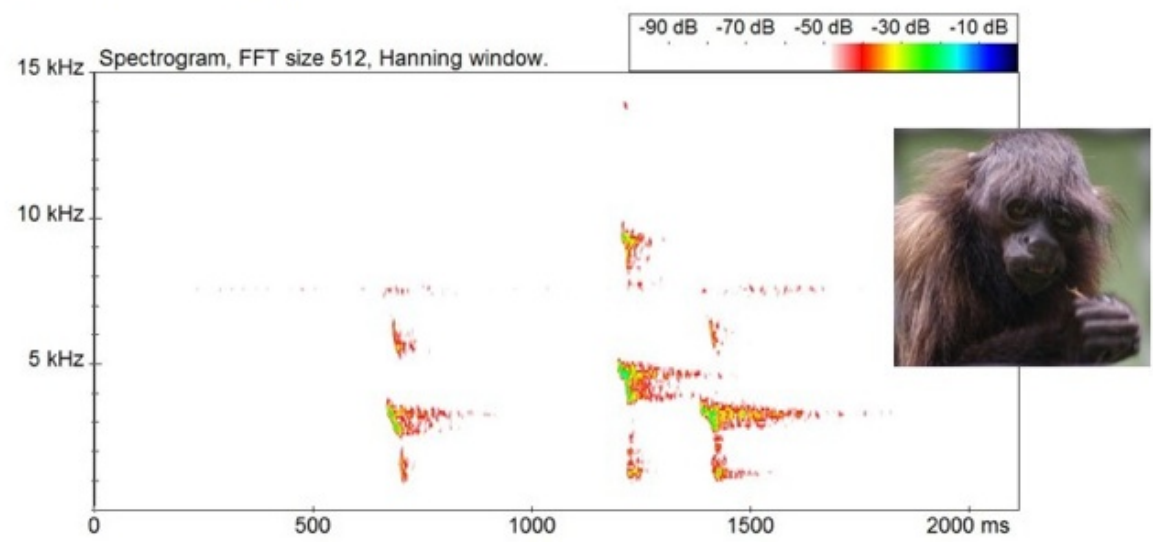

Figure 1. Spectrograms showing titi monkey and uacari calls. Call A - chirp: Callicebus nigrifrons alarm calls to raptors; Call B - cheeps: titi monkey alarm calls to terrestrial (titi monkey calls described in Cäsar et al. 2012a); Tchó call (also known as bi koh: e.g. Barnett 2010): Cacajao ouakary alarm call sequence (Cacajao call described in Bezerra et al. 2010a). The Cacajao tchó call is also used in other contexts and its physical structure changes slightly according to the context. Photos: titi monkey Cäsar C.; uakary monkey - Bezerra B. Spectrograms made using Batsound 3.1. 
behavioural contexts (Fontaine 1981; Bezerra et al. 2010a). Titi monkeys are reported to engage in duet calling (i.e., call sequences emitted by male and female pairmates), which may function in resource and territorial defence (e.g. Caselli et al. 2014; Müller and Anzenberger 2002; Robinson 1981). Several calls described for titi monkeys are linked to predation risk, perhaps reflecting the high overall level of predation risk for the genus (e.g. CisnerosHeredia et al. 2005; de Luna et al. 2010; Sampaio and Ferrari 2005; Electronic supplementary material 1 ).

Titi monkeys are known among primatologists for their apparently meaningful alarm calling (e.g. Cäsar and Zuberbuhler 2012; Cäsar et al. 2012a). Meaning-attributed signals transmit information about the events or objects of the environment considering the signal receiver's perspective/behavioural response (Wheeler and Fitcher 2015). Besides being produced in context-specific ways, these signals must elicit specific adaptive responses in listeners (e.g. Wheeler and Fitcher 2015). Titi monkeys produce three alarm call types in response to their main predators. Chirps (call A) are daily given in response to different raptors species; while cheeps (call B) are usually given in response to terrestrial predators. Playbacks of these two calls indicate that each elicits appropriate anti-predator behaviours (Cäsar et al. 2012b). The third call type, squeak (call $\mathrm{C}$ ), is not very specific; it is usually given when there is some intention to move (Cäsar et al. 2012a), but it is unknown if this call elicits a predator-specific response. These calls are produced both singly and at the beginning of different alarm call sequences (Cäsar et al. 2012a; 2013). Other call types, typically loud and conspicuous, are also produced later in titi monkeys alarm calling sequences, especially in response to terrestrial predators (Cäsar and Zuberbühler 2012). However, the function and meaning of some of these calls and respective sequences has still to be tested. It is important to point out that studies made by Cäsar and collaborators focused on one titi monkey species in a fairly well-preserved area (i.e. relatively low anthropogenic pressure). Thus, further studies would be necessary on other titi species living in preserved and disturbed habitats to add to our understanding of how fragment size and structure, predator presence and absence, predator type and anthropogenic pressures, might influence the vocalizations produced by titi monkeys in general.

Alarm calls have also been reported for the other pitheciid genera (e.g., cuxius: Barnett el al. 2017, Martins et al. 2005; Silva and Ferrari 2009; van Roosmalen et al. 1981; sakis: Henline 2007; Rettig 1978; uacari: Barnett et al. 2011; Bezerra et al. 2010a,b; Fontaine 1981). However, no further studies have been conducted to verify the meaning attributed to these signals. Overall, most primates vocalize when threatened by a predator, and the study of these alarm signals has proved particularly valuable for examining the cognitive processes in non-human animals (Zuberbühler 2006). As shown above for titi monkeys, there is evidence that pitheciids possess a complex alarm calling system. To attain greater understanding of the evolutionary aspects behind the variety and form of communication signals in this family, further focused studies are required.

Food/feeding associated calls have been reported for cuxius (van Roosmalen et al. 1981), uacaris (Barnett 2010; Bezerra et al. 2010a) and titi monkeys (Cäsar and Zuberbühler 2012). Further experimentation needs to be conducted to investigate, among 
other considerations, whether these calls function to attract conspecifics to the food source (e.g. Di Bitetti 2003; Dittus 1984), or to announce food ownership and thus avoid conflicts between group members (e.g. Gros-Louis 2004).

\section{Call combinations}

The use of combinations of calls has been observed in uacaris and titi monkeys (Bezerra et al. 2010b; Cäsar et al. 2012a; Robinson 1979), and there is recent strong evidence that call sequence may be meaningful (Callicebus nigrifrons: Cäsar et al. 2012b 2013). Here, individuals produce uniquely composed alarm call sequences, consisting of two main call types, call $A$ and B (Cäsar et al. 2013, Figure 2). These calls convey both information about the location and type of predator within the same utterance (Cäsar et al. 2013). In response to a feline predator, the locational information is conveyed by the first call of each sequence, while in responses to predatory raptors, the locational response is conveyed by the later parts of the sequence (Cäsar et al. 2013). Some of these sequences are meaningful to others, as conspecifics respond in specific ways, even in the absence of the referent in this case a predator (Cäsar et al. 2012b).

\section{Call playbacks}

Playback has proven successful in eliciting vocal responses in sakis (Di Fiore et al. 2007; Fernandez-Duque et al. 2013), uacaris and titi monkeys (e.g. Cäsar, unpublished data; Chagas and Ferrari 2010; Dacier et al. 2011; Jerusalinsky 2013; Marques et al. 2013; Melo and Mendes 2000, Printes et al. 2011; Souza-Alves and Ferrari 2010). Cacajao ouakary responded more strongly to calls from neighbouring groups than from its own group (Bezerra et al. 2010b). This suggests that a certain level of territorial defence does exist for the species, despite the low levels of agonistic interactions observed (i.e. less than $1 \%$ of their activity budget Barnett 2010; Bezerra 2010; Bezerra et al. 2011a,b), and the large inter-individual distances and extensive daily ranges recorded (Barnett 2010; Barnett and Shaw 2014; Bezerra 2010; Bezerra et al. 2011). In Pithecia aequatorialis, playback experiments provided preliminary evidence that males respond more strongly to a potential intruder than do females (Di Fiore et al. 2007; Fernandez-Duque et al. 2013), suggesting that male $P$. aequatorialis may have a role in group defence. The calls could possibly be used to avoid costly agonistic interactions in both uacaris and sakis. As shown above, call playback in titi monkey species has revealed the potential function and meaning of their alarm calls (Cäsar et al. 2013).

Call playback has already been used successfully for distribution surveys of several titi monkey species, including Callicebus coimbrai (Aldrich et al. 2008; Chagas and Ferrari 2010; Jerusalinsky 2013; Jerusalinsky et al. 2006; Souza-Alves and Ferrari 2010), Plecturocebus discolor (formerly Callicebus discolor) (Dacier et al. 2011), Callicebus barbarabrownae (Marques et al. 2013; Printes et al. 2011), Plecturocebus modestus (formerly Callicebus modestus) (Martinez and Wallace 2016), Callicebus nigrifrons (Gestich et al. 2017), and Plecturocebus olallae (formerly Callicebus olallae) (Martinez and Wallace 2016). In all cases, the technique was found to increase the likelihood of encountering the target animals. For example, in a comprehensive study of the geographic distribution of C. coimbrai, over $71 \%$ of reports (in 49 forest fragments of varying 


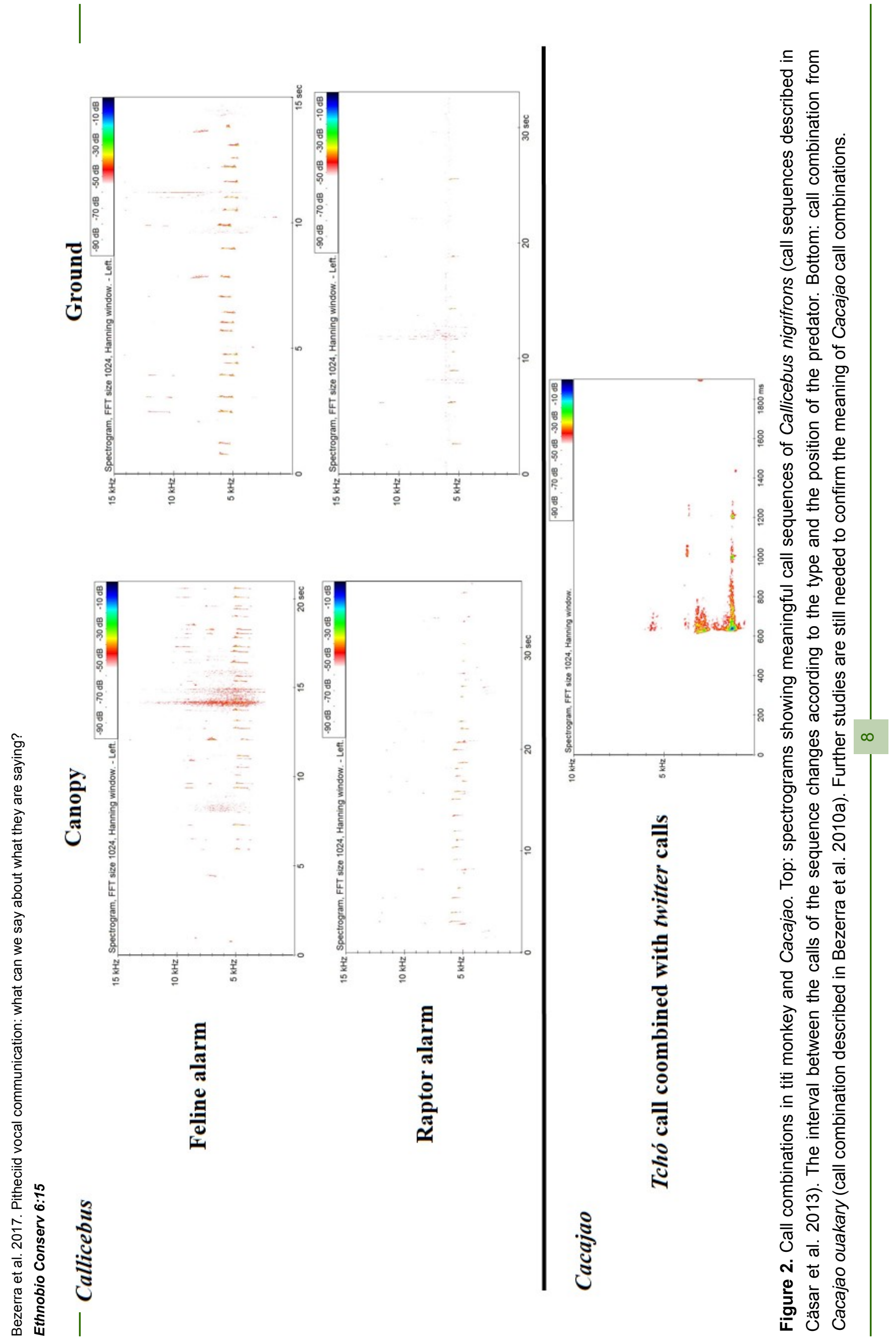


size) resulted from the detection of spontaneous vocalizations and vocal responses to call playbacks by this and other titi monkey species (Jerusalinsky 2013). This study used territorial duet calls from Callicebus personatus and obtained responses from $C$. coimbrai and $C$. barbarabrownae, showing that congeneric call playbacks can be also effective for species surveys. These species are very closely related and were once considered to be a single species (see Byrne et al. 2016 for a summary of past taxonomic arrangements).

\section{How can we use the current knowledge for animal welfare?}

Since calls can be used as indicators of behavioural patterns (e.g. Bezerra et al. 2010a; Caselli et al. 2014; Henline 2007), and appear useful for monitoring social communication and dynamics (McCowan and Rommeck 2006), vocalizations could potentially be integrated into standard animal welfare assessment for some pitheciid species. By comparing the similarities of the vocal repertoires of captive populations with those used by wild conspecifics, zookeepers and laboratory managers could provide the necessary stimuli to expand the vocal repertoire (and perhaps enrich the environment) of captive animals. This could be made possible for Cacajao ouakary (Bezerra et al. 2010a), Pithecia irrorata (Adams and Erhart 2009), Pithecia pithecia (Henline 2007), and some titi monkeys (Electronic Supplementary Material 1). The study and description of vocal repertoires of wild pitheciids for this purpose should be encouraged.

It is not only the expansion of the vocal repertoire in captive animals which should be used in animal welfare practices, however, as we should also consider monitoring specific calls. In captive capuchin monkeys, for instance, the frequent use of terrestrial predator alarms seems to be associated with higher levels of stress hormones and poorly enriched environments (Jacobsen et al. 2010). Monitoring alarm calls in captive pitheciids could be an interesting initial study. Such calls could be easily quantified for titi monkey species due to their well-defined and evident alarm calls (Cäsar et al. 2012b 2013, Fig 2). In uacari species, the lack of evident described predator-specific alarm calls (Mourtè and Barnett 2014) would make it harder for such quantifications. Nevertheless, they have multi-context calls that present subtle variations in agonistic/alarming situations (i.e. the tchó call), becoming shorter and higher pitched (Bezerra et al. 2010a). Thus, considering the structure of multi-context calls in pitheciids would be an alternative route to monitor alarming situations. The latter would require non-invasive passive recorders and automated analyses software such as that produced by Wildlife Acoustics Inc. (http://www.wildlifeacoustics.com). Such arrays could be potential tools for such a monitoring system in captive settings.

\section{Trends in Pitheciidae vocal communication studies}

Research on pitheciid vocalizations has revealed information on repertoire size, call structure, context and propagation, as well as meaning-attributed signals. Although there are difficulties when investigating pitheciid vocal communication in the wild, the increasing number of publications indicates an expanding interest and effort by researchers to investigate these elusive and highly threatened primates. As might be expected from the relatively widespread 
geographic distribution and large number of titi monkey species (Silva Júnior et al. 2013; see, however, Marsh 2014 for number of saki species), approximately $64 \%$ of the tallied studies focused on these primates (Electronic Supplementary Material 1). Titi monkey populations are distributed throughout the Amazon area, as well as northeast and southeast Brazil (Silva Junior et al. 2013). Reasonable road networks in the non-Amazonian areas of Brazil facilitate access to many titi monkey populations and field sites. This situation contrasts with uacari, cuxius and sakis populations, which are concentrated in the highly inaccessible Amazon basin, where poor infrastructure means there is usually a need for boat expeditions to locate study populations, resulting in greater logistic and financial challenges (Pinto et al. 2013).

Despite the advances in the knowledge of pitheciid vocal communication, information on the majority of the species is still lacking. For instance, we have vocal repertoires for only about $12 \%$ of the 61 pitheciid species, and most of the knowledge currently available on meaning of calls (i.e. contextspecific signals that provoke a response that is context independent - Wheeler and Fitcher 2015) comes from titi species. Future efforts should also investigate vocalizations of other members of the pitheciid clade. Studies of captive animals could also add to our understanding of vocal communication in this group. Despite the limitations posed by studies of captive animals (e.g. confined, often-unnatural conditions), captive studies provide logistically viable approaches to studying the vocal behaviour of animals that are challenging to study in the wild. For uacaris and sakis particularly, studies of semi-captive animals would be extremely valuable in this context, as they could provide larger group sizes (or at least natural sub-group sizes) from which to obtain a valid range of the call types emitted by these monkeys.

The vocal repertoires described for titi monkeys and sakis have the expected sizes for these genera, considering their relatively small social group sizes (McComb and Semple 2005). However, uacari groups can contain over 100 individuals (Barnett 2010; Barnett et al. 2005; Bowler et al. 2012; Defler 2003), and a larger vocal repertoire would then be expected given that, in primate lineages, vocal repertoire size generally increases with increasing group size (McComb and Semple 2005). Also, vocal repertoire size in non-human primates seems to be directly related social bonding reflected in time dedicated to grooming in their activity budget (McComb and Semple 2005). The three groups of $C$. ouakary investigated by Bezerra et al. (2011) showed a fission-fusion social system. The "subgroups" observed in this study were relatively small (maximum counts were: 5, 15 , and 26 individuals) when compared to full group sizes previously reported for uacaris (including uacari groups inhabiting the same study site - Barnett 2010; Barnett et al. 2005). For pitheciid primates with a fission-fusion social system, it seems that it is not the full group size, but the subgroup size and structure (the latter based on Kappeler and van Schaik 2002) that is likely to drive vocal repertoire size. This would be in line with the theory of a social-vocal coevolution of communicative abilities proposed for primate species by Bouchet et al. (2013). Also, very little time appears to be dedicated to social grooming by the groups of $C$. ouakary investigated by Bezerra and collaborators (i.e., $\sim 1 \%$ of their activity budget, Barnett 2010, Bezerra et al 2011), and this may play a role in the relatively small vocal repertoire size. The trend "group 
size directly related to small vocal repertoire" can be observed in pitheciids if we consider the few studies that attempted full repertoire descriptions. Nevertheless, an increase in studies of pitheciid vocal behaviour should allow a better understanding of their vocal abilities and how evolution has shaped their social structure, behaviour and communication. Investigation of social calls between individuals as they groom and mate, between mother and offspring, or between offspring as they play, would also be interesting topics for investigation. Studies on such calls are known in several primate species (Arbid et al. 2008), but are still lacking in pitheciids. Such studies could provide not only context-specific information about the calls, but also insights into call ontogeny in pitheciids.

While the number of call types certainly contributes to vocal complexity, it is not only factor involved (Bouchet et al. 2013; Kershenbaum 2014; Krams et al. 2012). Call combination, for instance, may also play a big role in this. The combination of calls (which individually can themselves have defined meanings) into meaningful sequences increases the variety of messages that can be generated (e.g. Arnold and Zuberbühler 2006; Cleveland and Snowdon 1982; Marler et al. 1992; Mitani and Marler 1989; Robinson 1984; Robinson 1979; Zuberbühler 2002). The production of meaningful call sequences has been reported in Callicebus nigrifrons (Cäsar et al. 2012b 2013), in other New World monkeys including cotton-top tamarin (e.g., Saguinus oedipus: Cleveland and Snowdon 1982), and weeper capuchins (Cebus olivaceus: Robinson 1984), and in Old World primates, including putty-nosed monkeys (Cercopithecus nictitans: Arnold and Zuberbühler 2006), Diana monkeys (Cercopithecus diana: Candiotti et al. 2012;
Zuberbühler 2002), Campbell's monkeys (Cercopithecus campbelli campbelli: Ouattara et al. 2009), guereza colobus (Colobus guereza; Schel and Zuberbühler 2012), white-handed gibbons (Hylobates lar, Clarke et al. 2006), and chimpanzees (Pan troglodytes: Crockford and Boesch 2005; and $P$. paniscus: Clay and Zuberbühler 2009).

Evidence of meaningful acoustic signals in pitheciid primates has come from Callicebus nigrifrons alarm calls (Cäsar et al. 2012b, 2013). These signals have been observed in several other non-human primates in a variety of contexts, including food-associated calls (chimpanzees, Pan troglodytes; Slocombe and Zuberbühler 2005 and tufted capuchin monkeys, Sapajus apella nigritus; Di Bitetti 2003), social screams (rhesus macaques, Macaca mulatta; Gouzoules et al. 1984), and various studies on predator-specific alarm calls (e.g. vervet monkeys, Chlorocebus aethiops, Seyfarth et al. 1980; Diana monkeys, Cercopithecus diana, Zuberbühler et al. 1997; Campbell's monkeys, Cercopithecus campbelli, Zuberbühler 2001; moustached tamarins, Saguinus mystax, Kirchhof and Hammerschmidt 2006; tufted capuchin monkeys, Sapajus apella nigritus, Wheeler 2010).

Call playback is not only useful to investigate meaning of pitheciid calls, but also to conduct distribution surveys, which are extremely important for conservation of field sites and the species that inhabit them. Given that primate calls are generally species-specific and readily assignable to the vocalizing species (Bradbury and Vehrencamp 2011), they can be used in field surveys both by recording and identifying vocalizations, and also via monitoring responses to call playbacks that assist with attracting or locating animals and estimating 
population abundance (e.g. Bezerra et al. 2010b; Gestich et al. 2016; Plumptre et al. 2013; Chagas and Ferrari 2010). Even though playback of calls from congeneric species may elicit a vocal response in pitheciid primates (Jerusalinsky 2013), recording of acoustic responses and analysis of their physical structure may help assigning calls to species. Pitheciid monkeys have shown marked vocal responses to call playbacks, thus, we believe this technique should be considered for field use whenever rapid assessments of a species' presence are needed, but visual contact is difficult to obtain and maintain. A standard call playback survey protocol should be adopted, so that comparative information can be obtained from simple field-site assessments. The 'lure counts' method as described in Plumptre et al. (2013), where by the researcher actively attracts the animals by doing call playbacks and estimate animal distances to sound source by using a detection function model previously established, could be used as a standard protocol.

\section{CONCLUSIONS}

In summary, the information available on the vocal communication systems of pitheciid species is still very limited, and is reduced even further when the recent taxonomic revisions of sakis (Marsh 2014) and titi monkeys (Byrne et al. 2016) are considered. Basic information on vocal repertoires and acoustic communication are still lacking for most pitheciid species (Bezerra et al. 2013). This lack of information is a major obstacle to testing proposals concerning the evolution of pitheciid communication, and for potentially locating threatened species in habitats in which they are difficult to detect visually.
Existing data on pitheciid vocal repertoires could be used for immediate conservation and welfare practices. Vocalizations can, potentially, represent a rapid, simple and non-invasive method of assessing the level of stress/wellbeing of the animals via the identification and monitoring of stressassociated calls. Three mains ways could be explored in pitheciids to promote welfare in captive animals: 1) the use of environmental enrichment to expand the vocal repertoire, providing the necessary behavioural stimuli for such expansion; 2) monitoring of specific calls, such as alarm-related signals, that may indicate stress and poorly enriched enclosures, and 3) monitoring of multicontext calls structure which may also indicate stress-related situations.

Advances would doubtless be made if researchers were to share high quality sound files of pitheciid vocalizations. This would facilitate species identification and consequently call playbacks could be more widely used to aid locating pitheciid species in the wild. The creation of an internetbased, freely available pitheciid vocal library would be ideal for that purpose. It should include high quality non-compressed sound files (i.e., WAV format) covering a wide range of specified behavioural contexts representative of as many pitheciid species and individuals as possible. Such sound library could be available, for example, at the Pitheciine Action Group (PAG) website. We will attempt the creation of such sound library and hope to launch it on PAG website in early 2018. Also, an alternative route would be to integrate our pitheciid sound library to an existing one such as the Macaulay Library (http://macaulaylibrary.org) and the Primate Information Network (http://pin.primate.wisc.edu). 


\section{ACKNOWLEDGEMENTS}

We thank Cyndie Thompson, Joanna Setchell and two anonymous reviewers for valuable comments in early versions of this manuscript. MB is supported by a FACEPE scholarship (\#IBPG-0544-2.05/13).

\section{REFERENCES}

Adams DB, Erhart EM (2009) Differential response to predators in the Gray's baldfaced saki monkey (Pithecia irrorata): a playback experiment. American Journal of Physical Anthropology 48:75

Aldrich BC, Molleson L, Nekaris KAI (2008) Vocalizations as a conservation tool: an auditory survey of the Andean titi monkey Callicebus oenanthe Thomas, 1924 (Mammalia: Primates: Pitheciidae) at Tarangue, Northern Peru. Contributions to Zoology 77:1-6

Arbid MA, Liebal K, Pika S (2008) Primate vocalization, gesture and the evolution of human language. Current Anthropology 49:1053-1076

Arnold K, Zuberbühler K (2006) Semantic combinations in primate calls. Nature 441:303

Barnett AA (2010) Diet, habitat use and conservation ecology of the golden-backed uacari, Cacajao melanocephalus ouakary, in Jaú National Park, Amazonian Brazil. PhD Thesis, Roehampton University, London, UK

Barnett AA, Boyle SA, Thompson CL (2016) Pitheciid research comes of age: past puzzles, current progress, and future priorities. American Journal of Primatology 78: 487-492

Barnett AA, Castilho CV, Shapley RL, Anicácio A (2005) Diet, habitat selection and natural history of Cacajao melanocephalus ouakary in Jaú National Park, Brazil. International Journal of Primatology 26:949-969

Barnett AA, Schiel V, Deveny A, Valsko J, Spironello WR, Ross C (2011) Predation on Cacajao ouakary and Cebus albifrons (Primates: Platyrrhini) by harpy eagles. Mammalia 75:169-172
Barnett AA, Shaw P (2014) More food or fewer predators? The benefits to birds of associating with a Neotropical primate varies with their foraging strategy. Journal of Zoology 294:224-233

Barnett AA, Silla JM, de Oliveira T, Boyle SA, Bezerra BM, Spironello WR, Setz EZF, Soares R, de Albuquerque Teixeira S, Todd LM, Pinto LP (2017) Run, hide or fight: anti-predation strategies in Endangered red-nosed cúxiu (Chiropotes albinasus, Pitheciidae) in southeastern Amazonia. Primates 58: 353-360.

Bezerra BM (2010) Behaviour and vocal communication in golden-backed uakaris: Cacajao melanocephalus. PhD Thesis, University of Bristol, Bristol, UK

Bezerra BM, Barnett AA, Souto A, Jones G (2011a) Ethogram and natural history of golden-backed uakaris (Cacajao melanocephalus). International Journal of Primatology 32:46-68

Bezerra BM, Souto AS, Jones G (2010a) Vocal repertoire of golden-backed uakaris (Cacajao melanocephalus): call structure and context. International Journal of Primatology 31:759-778

Bezerra BM, Souto AS, Jones G (2010b) Responses of golden-backed uakaris, Cacajao melanocephalus, to call playback: implications for surveys in the flooded igapó forest. Primates 51:327-336

Bezerra BM, Souto AS, Jones G (2011b) Perspectives in primate bioacoustics. In: Potocki E, Krasiñski J (eds) Primatology: Theories, methods and research. Nova Science Publishers, Hauppauge, NewYork, pp. 1-28

Bezerra BM, Souto AS, Jones G (2012) Propagation of the loud "tchó" call of goldenbacked uakaris, Cacajao melanocephalus, in the blackwater-swamp forests of the upper Amazon. Primates 53:317-325

Bezerra BM, Barnett A, Souto AS, Jones G (2013) Vocal communication in Cacajao, Chripotes and Pithecia: current knowledge and future directions. In: Veiga $L M$, Barnett $A B$, Ferrari SF, Norconk MA (eds) Evolutionary Biology and conservation of titis, sakis and uakaris. Cambridge University Press, Cambridge, pp. 303-310 
Bouchet H, Blois-Heulin C, Lemasson A (2013) Social complexity parallels vocal complexity: a comparison of three non-human primate species. Frontiers in Psychology doi: 10.3389/fpsyg.2013.00390

Bowler M, Knogge C, Heymann EW, Zinner D (2012) Multilevel societies in New World Primates? Flexibility may characterize the organization of Peruvian red uakaris (Cacajao calvus ucayalii). International Journal of Primatology 33:1110-1124

Bradbury JW, Vehrencamp SL (2011) Principles of animal communication. 2 ed. Sinauer Associates, Sunderland, MA

Brown CH, Waser PM (1988) Environmental influences on the structure of primate vocalizations. In: Todt $D$, Goedeking $P$, Symmes D (eds). Primate Vocal Communication. Springer, Berlin, Heidelberg.

Buchanan DB, Mittermeier RA, van Roosmalen MGM (1981) The saki monkeys, genus Pithecia. In: Coimbra-Filho RA, Mittermeier RA (eds) Ecology and behaviour of Neotropical primates. Academia Brasileira de Ciências, Rio de Janeiro, pp. 391-417

Byrne $\mathrm{H}$, Rylands $A B$, Carneiro JC, Alfaro JWL, Bertuol F, da Silva MN, Messias M, Groves CP, Mittermeier RA, Farias I, Hrbek T (2016) Phylogenetic relationships of the New World titi monkeys (Callicebus): first appraisal of taxonomy based on molecular evidence. Frontiers in Zoology 13:1-26

Candiotti A, Zuberbühler K, Lemasson A (2012) Context-related call combinations in female Diana monkeys. Animal Cognition 15:327-339

Cäsar C (2011) Anti-predator behaviour of black-fronted titi monkeys (Callicebus nigrifrons). $\mathrm{PhD}$ thesis, University of Saint Andrews, UK

Cäsar C, Zuberbühler K (2012) Referential alarm calling behaviour in New World primates. Current Zoology 58:680-697

Cäsar C, Zuberbuhler K, Young RJ, Byrne RW (2013) Titi monkey call sequences vary with predator location and type. Biology Letters 9:20130535-20130535

Cäsar C, Byrne R, Young RJ, Zuberbühler $K$ (2012a) The alarm call system of wild blackfronted titi monkeys, Callicebus nigrifrons. Behavioral Ecology and Sociobiology 66:653-667
Cäsar C, Byrne R, Hoppitt W, Young RJ, Zuberbühler K (2012b) Evidence for semantic communication in titi monkey alarm calls. Animal Behaviour 84:405-411

Caselli CB, Mennill D, Bicca-Marques JC, Setz EZF (2014) Vocal Behavior of black-fronted titi monkeys (Callicebus nigrifrons): acoustic properties and behavioral contexts of loud calls. American Journal of Primatology 76:788-800

Chagas R, Ferrari SF (2010) Population parameters of the endangered titi monkey, Callicebus coimbrai Kobayashi and Langguth, 1999, in the fragmented landscape of southern Sergipe, Brazil. Brazilian Journal of Biology 71:569-575

Cisneros-Heredia DF, León-Reyes A, Seger S (2005) Boa constrictor predation on a titi monkey, Callicebus discolor. Neotropical Primates 13:11-12

Clarke E, Reichard UH, Zuberbühler K (2006) The syntax and meaning of wild gibbon songs. PLoS ONE 1:e73

Clay Z, Zuberbühler K (2009) Food-associated calling sequences in bonobos. Animal Behaviour 77:1387-1396.

Cleveland J, Snowdon CT (1982) The complex vocal repertoire of the adult cotton-top tamarin Saguinus oedipus oedipus. Zeitschrift für Tierpsychologie 58:231-270

Crockford C, Boesch C (2005) Call combinations in wild chimpanzees. Behaviour 142:397-421

Dacier A, de Luna AG, Fernandez-Duque E, Di Fiore A (2011) Estimating population density of Amazonian titi monkeys (Callicebus discolor) via playback point counts. Biotropica 43:135-140

Dalponte JC, Silva FE, Silva-Júnior JS (2014) New species of titi monkey, genus Callicebus Thomas, 1903 (Primates, Pitheciidae), from Southern Amazonia, Brazil. Papéis Avulsos de Zoologia 54:457-472

de Luna AG, Sanmiguel $R$, Di Fiore A, Fernandez-Duque E (2010) Predation and predation attempts on red titi monkeys (Callicebus discolor) and equatorial sakis (Pithecia aequatorialis) in Amazonian Ecuador. Folia Primatologica 81:86-95 
Defler TR (2003) Primates de Colombia. Conservation International, Bogotá

Di Bitetti M (2003) Food-associated calls of tufted capuchin monkeys (Cebus apella nigritus) are functionally referential signals. Behaviour 140:565-592

Di Fiore A, Fernandez-Duque E, Hurst D (2007) Adult male replacement in socially monogamous equatorial saki monkeys (Pithecia aequatorialis). Folia Primatologica 78:88-98

Dixson A, Anderson M (2001) Sexual selection and the comparative anatomy of reproduction in monkeys, apes, and human beings. Annual Review of Sex Research 12:121-144

Dittus WPJ (1984). Toque macaque food calls: semantic communication concerning food distribution in the environment. Animal Behaviour 32:470-477

Ey E, Fischer F (2009) The "acoustic adaptation hypothesis" - a review of the evidence from birds, anurans and mammals. Bioacoustics 19:21-48

Fernandez-Duque E, Di Fiore A, de Luna AG (2013) Pair-mate relationships and parenting in ecuatorial saki monkeys (Pithecia aequatorialis) and red titi monkeys (Callicebus discolor) of Ecuador. In: Veiga LM, Barnett AB, Ferrari SF, Norconk MA (eds) Evolutionary biology and conservation of titis, sakis and uacaris. Cambridge University Press, Cambridge, pp. 295-302

Ferrari SF, Guedes PG, Figueiredo W, Barnett AA (2014) Reconsidering the nomenclature of the black-faced uacaris (Cacajao melanocephalus group, sensu Hershkovitz, 1987) from the northern Amazon basin. Zootaxa 3866:353-370

Fichtel C, Manser M (2010) Vocal communication in social groups. In: Kappeler $P$ (eds). Animal Behaviour: Evolution and Mechanisms. Springer, Berlin, Heidelberg, pp. 29-54.

Fischer J, Price T (2016). Meaning, intention, and inference in primate vocal communication. Neuroscience and Biobehavioral Reviews. https://doi.org/10.1016/j.neubiorev.2016.10.014

Fontaine $\mathrm{R}$ (1981) The uakaris, Genus Cacajao. In: Coimbra-Filho A, Mittermeier RA (eds) Ecology and behavior of Neotropical Primates. Academia Brasileira de Ciências, Rio de Janeiro, pp. 443-493.
Gestich CC, Caselli CB, Nagy-Reis MB, Setz EZF, da Cunha RGT (2017) Estimating primate population densities: the systematic use of playbacks along transects in population surveys. American Journal of Primatology 79: e22586. doi:10.1002/ajp.22586.

Gil-da-Costa, R (2007). Howler monkeys and harpy eagles: a communication arms race. Gursky-Doyen S, Nekaris KAl (eds.) Primate anti-predator strategies. Springer, pp. 289-307

Gouzoules S, Gouzoules H, Marler P (1984) Rhesus monkey (Macaca mulatta) creams: representational signalling in the recruitment of agonistic aid. Animal Behaviour 32:182-193

Groves C (2001) Primate taxonomy. Smithsonian Institution Press, Washington

Groves C (2005) Order Primates. In: Wilson DE, Reeder DM (eds) Mammals of the world: a taxonomic and geographic reference. 3 ed. The Johns Hopkins University Press, Baltimore, pp. 111-184

Gros-Louis J (2004) The function of foodassociated calls in white-faced capuchin monkeys, Cebus capucinus, from the perspective of the signaller. Animal Behaviour $67: 431-440$

Henline WT (2007) Vocal repertoire of whitefaced sakis (Pithecia pithecia). MSc dissertation, Eastern Kentucky University, Kentucky, USA

Hewson CJ (2004) Do vocalizations tell us anything about animal welfare? Canadian Veterinary Journal 45:621-624

IUCN (2017) The IUCN red list of threatened species. [http://www.iucnredlist.org.] Accessed 27 June 2017

Jacobsen KR1, Mikkelsen LF, Hau J (2010) The effect of environmental enrichment on the behavior of captive tufted capuchin monkeys (Cebus apella). Laboratory Animals (NY) 39:269-77

Jerusalinsky L (2013) Distribuição geográfica e conservação de Callicebus coimbrai Kobayashi and Langguth, 1999 (Primates Pitheciidae) na mata atlântica do nordeste Brasileiro. PhD Thesis, Universidade Federal da Paraíba, João Pessoa, Brazil 
Jerusalinsky L, Oliveira MM, Pereira RF, Santana V, Bastos PCR, Ferrari SF (2006) Preliminary evaluation of the conservation status of Callicebus coimbrai Kobayashi and Langguth, 1999 in the Brazilian state of Sergipe. Primate Conservation 21:25-32

Kappeler PM, van Schaik CP (2002) Evolution of primate social systems. International Journal of Primatology 23:707-740

Kershenbaum A (2014) Entropy rate as a measure of animal vocal complexity. Bioacoustics 23:195-208

Kinzey WG, Rosenberger AL, Heisler PS, Prowse DL, Trilling JS (1977) A preliminary field investigation of the yellow-handed titi monkeys, Callicebus torquatus torquatus, in northern Peru. Primates 18:159-181

Kirchhof J, Hammerschmidt K (2006) Functionally referential alarm calls in tamarins (Saguinus fuscicollis and Saguinus mystax) - evidence from playback experiments. Ethology 112:346-354

Krams I, Krama T, Freeberg TM, Kullberg C, Lucas JR (2012) Linking social complexity and vocal complexity: a parid perspective. Philosophical Transactions of the Royal Society B 367:1879-1891

Kroodsma DE, Miller EH (1996) Ecology and evolution of acoustic communication in birds. Cornell University Press, Ithaca

Linhart P, Ratcliffe VF, Reby D, Spinka M. (2015). Expression of emotional arousal in two different piglet call types. PLoS One 10:e0135414

Maciej P, Ndao I, Hammerschmidt K, Fischer J (2013) Vocal communication in a complex multi-level society: constrained acoustic structure and flexible call usage in Guinea baboons. Frontiers in Zoology 10:58 https://doi.org/10.1186/1742-9994-10-58.

Marler P, Evans C, Hauser MD (1992) Animal signals: reference, motivation or both? In: Papoucek $H$, Jürgens $U$, Papoucek $M$ (eds) Nonverbal vocal communication: comparative and developmental approaches. Cambridge University Press, Cambridge, pp. 66-86

Marques ELN, Beltrão-Mendes R, Ferrari SF (2013) Primates, Pitheciidae, Callicebus barbarabrownae Hershkovitz, 1990: New localities for the critically endangered titi monkey in the São Francisco basin, state of Sergipe, Brazil. Check List 9:113-115
Marsh LK (2014) A taxonomic revision of the saki monkeys, Pithecia Desmarest, 1804. Neotropical Primates 21:1-65

Martinez J, Wallace RB (2016) Ecological and behavioural factors influencing territorial call rates for the Bolivian titi monkeys, Plecturocebus modestus and Plecturocebus olallae. Folia Primatologica 87:279-290

Martins SS, Lima EM, Silva-Júnior JS (2005) Predation of a bearded saki (Chiropotes utahicki) by a harpy eagle (Harpia harpyja). Neotropical Primates 13:7-10

McComb K, Semple S (2005) Coevolution of vocal communication and sociality in primates. Biology Letters 1:381-385

McCowan B, Rommeck I (2006) Bioacoustic monitoring of aggression in group-housed rhesus macaques. Journal of Applied Animal Welfare Science 9:261-26

Melo FR, Mendes SL (2000) Emissão de gritos longos por grupos de Callicebus nigrifrons e suas reações a playback. In: Alonso $C$, Langguth A (eds) A Primatologia do Brasil 7. Ed Universitária, Sociedade Brasileira de Primatologia, João Pessoa, pp. 215-222

Mitani JC, Marler P (1989) A phonological analysis of male gibbon singing behavior. Behaviour 109:20-45

Mourthé I, Barnett AA (2014) Crying tapir: the functionality of errors and accuracy in predator recognition in two Neotropical highcanopy primates. Folia Primatologica 85: 379398

Moynihan M (1966) Communication in the Titi monkey, Callicebus. Journal of Zoology 150:77127.

Müller AE, Anzenberger G (2002) Duetting in the titi monkey Callicebus cupreus: structure, pair specificity and development of duets. Folia Primatologica 73:104-115

Norconk MA (2006) Long-term study of group dynamics and female reproduction in Venezuelan Pithecia pithecia. International Journal of Primatology 27:653-674

Norconk MA (2007) Sakis, uakaris, and titi monkeys. In: Campbell C, Fuentes A, MacKinnon KG, Panger M, Bearder SK (eds) Primates in perspective. Oxford University Press, Oxford, pp. 122-139 
Ouattara K, Lemasson A, Zuberbühler K (2009) Campbell's monkeys concatenate vocalizations into context-specific call sequences. Proceedings of the National Academy of Sciences 106:22026-22031

Pinto LP (2008) Ecologia alimentar do cuxiude-nariz-vermelho Chiropotes albinasus (Primates: Pitheciidae) na Floresta Nacional do Tapajos, Pará. PhD Thesis, Universidade Estadual de Campinas, Brazil

Pinto LP, Barnett AA, Bezerra BM, Boubli JP, Bowler M, Cardoso NA, Caselli CB, Rodriguez JO, Santos RR, Setz EZF, Veiga LM (2013) Why we know so little: the challenges of fieldwork on the Pitheciids. In: Veiga LM, Barnett $A B$, Ferrari SF, Norconk MA (eds) Evolutionary biology and conservation of titis, sakis and uacaris Cambridge University Press, Cambridge, pp. $145-150$

Plumptre AJ, Sterling EJ, Buckland S (2013) Primate census and survey techniques. In: Sterling EJ, Bynum N, Blair ME (eds) Primate ecology and conservation: a handbook of techniques. Oxford University Press. Oxford, pp. 10-26

Printes RC, Rylands AB, Bicca-Marques JC (2011) Distribution and status of the Critically Endangered blond titi monkey Callicebus barbarabrownae of northeast Brazil. Oryx 45:439-443

Rettig NL (1978) Breeding behavior of the harpy eagle Harpia harpyja. Auk 95:629-643

Robinson JG (1979) An analysis of the organization of vocal communication in the titi monkey Callicebus moloch. Zeitschrift fur Tierpsychologie 49:381-405

Robinson JG (1981) Vocal Regulation of Interand intragroup spacing during boundary encounters in the titi monkey, Callicebus moloch. Primates 22:161-172.

Robinson JG (1984) Syntactic structures in the vocalizations of wedge-capped capuchin monkeys Cebus olivaceus. Behaviour 90:46-79

Sampaio DT, Ferrari SF (2005) Predation of an infant titi monkey (Callicebus moloch) by a tufted capuchin (Cebus apella). Folia Primatologica 76:113-115

Schel AM, Zuberbühler K (2012) Predator and non-predator long-distance calls in Guereza colobus monkeys. Behavioural Processes 91:41-49
Semple S, Higham JP (2013) Primate signals: current issues and perspectives. American Journal of Primatology 75: 613-620

Seyfarth RM, Cheney DL, Marler P (1980) Vervet monkey alarm calls: semantic communication in a free-ranging primate. Animal Behaviour 28:1070-1094

Silva SSB, Ferrari SF (2009) Behavior patterns of southern bearded sakis (Chiropotes satanas) in the fragmented landscape of eastern Brazilian Amazonia. American Journal of Primatology 71:1-7

Silva-Junior JS, Figueiredo-Ready WMB, Ferrari SF (2013) Taxonomy and geographic distribution of the Pitheciidae. In: Veiga LM, Barnett AB, Ferrari SF, Norconk MA (eds) Evolutionary biology and conservation of titis, sakis and uacaris. Cambridge University Press, Cambridge, pp. 31-42

Sobroza TV, Cerqueda LS, Simões PI, Gordo M (2017) Vocal repertoire and its behavioral contexts in the pied tamarin, Saguinus bicolor. International Journal of Primatology. 38: 642. https://doi.org/10.1007/s10764-017-9971-z

Souza-Alves JP, Ferrari SF (2010) Responses of wild titi monkeys, Callicebus coimbrai (Primates: Platyrrhini: Pitheciidae), to the habituation process. Zoologia 27:861-866

Skowronski MD, Fenton BM (2009) Detecting bat calls: an analysis of automated methods. Acta Chiropterologica 11:191-203

Slocombe KE, Zuberbühler K (2005) Agonistic screams in wild chimpanzees (Pan troglodytes schweinfurthii) vary as a function of social role. Journal of Comparative Psychology 119:67-77

van Roosmalen MGM, Mittermeier RA, Milton K (1981) The bearded sakis, Genus Chiropotes. In: Coimbra-Filho AF, Mittermeier RA (eds) Ecology and Behavior of Neotropical Primates. Academia Brasileira de Ciências, Rio de Janeiro, pp. $419-442$

Veiga LM (2006) Ecologia e comportamento do cuxiú-preto (Chiropotes satanas) na paisagem fragmentada da Amazônia oriental. PhD Thesis, Universidade Federal do Pará, Brazil.

Veiga LM, Barnett AA, Ferrari SF, Norconk MA (2013) evolutionary biology and conservation of titis, sakis and uacaris. Cambridge University Press. 
Vermeer J, Tello-Alvarado JC (2015) The distribution and taxonomy of titi monkeys (Callicebus) in central and southern Peru, with the description of a new species. Primate Conservation 29:9-29

Wheeler BC (2010) Production and perception of situationally variable alarm calls in wild tufted capuchin monkeys (Cebus apella nigritus). Behavioral Ecology and Sociobiology 64:989-1000

Wheeler BC, Fischer J (2015) The blurred boundaries of functional reference: a response to Scarantino and Clay. Animal Behaviour 100:e9-e13
Zuberbühler K (2001) Predator-specific alarm calls in Campbell's guenons. Behavioral Ecology and Sociobiology 50:414-422

Zuberbühler K (2002) A syntactic rule in forest monkey communication. Animal Behaviour 63:293-299

Zuberbühler K (2006) Language evolution: the origin of meaning in Primates. Current Biology 16:123-125

Zuberbühler K, Noe R, Seyfarth RM (1997) Diana monkey long-distance calls: messages for conspecifics and predators. Animal Behaviour 53:589-604
Received: 27 June 2017

Accepted: 21 August 2017

Published: 16 September 2017 


\section{Electronic supplementary material 1 - List of studies related to vocal communication in Pitheciids.}

\section{Cacajao studies}

Barnett A, Shaw P, Spironello WR, MacLarnon A, Ross C. 2012. Sleeping site selection by goldenbacked uacaris, Cacajao melanocephalus ouakary (Pitheciidae), in Amazonian flooded forests. Primates 53:273-285.

Bezerra BM, Souto AS, Jones G. 2010. Vocal repertoire of golden-backed uakaris (Cacajao melanocephalus): Call structure and context. International Journal of Primatology 31:759-778.

Bezerra BM, Souto AS, Radford AN, Jones G. 2010. Brevity is not always a virtue in primate communication. Biology Letters 7:23-25.

Bezerra BM. 2010. Behaviour and vocal communication in golden-backed uakaris, Cacajao melanocephalus. [PhD. Thesis]. Bristol: University of Bristol. $153 \mathrm{p}$.

Bezerra BM, Souto AS, Jones G. 2010. Responses of golden-backed uakaris, Cacajao melanocephalus, to call playback: implications for surveys in the flooded Igapó forest. International Journal of Primatology 51:327-336.

Bezerra BM, Barnet A, Souto AS, Jones G. 2013. Vocal communication in Cacajao, Chiropotes and Pithecia: current knowledge and future directions. In: Veiga LM, Barnett AA, Ferrari SF, Norconk MA, editors. evolutionary biology and conservation of Titis, Sakis and Uacaris. Cambridge (UK): Cambridge University Press. 303 p.

Bezerra BM, Souto AS, Jones G. 2012. Propagation of the loud "tchó" call of golden-backed uakaris, Cacajao melanocephalus, in the black-swamp forests of the upper Amazon. Primates 53:317-325.

Barnett AA, Schiel V, Deveny A, Valsko J, Spironello WR, Ross C. 2011. Predation on Cacajao ouakary and Cebus albifrons (Primates: Platyrrhini) by harpy eagles. Mammalia 75:169-172.

Bowler M. 2007. The ecology and conservation of the red uacari monkey on the Yavarí river, Peru. [PhD Thesis]. Kent: University of Kent.

Boubli JP. 1997. Ecology of the black uacari monkey Cacajao melanocephalus melanocephalus in the Pico de Neblina National Park, Brazil. [PhD dissertation]. Berkeley: University of California. 218 p.

Fontaine R, 1981. The uakaris, genus Cacajao. In: Coimbra-Filho AF, Mittermeier RA, editors. Ecology and Behavior of Neotropical Primates. Rio de Janeiro: Academia Brasileira de Ciências. p 443-493.

\section{Callicebus studies (Genus currently split into Callicebus, Cheracebus, and Plecturocebus)}

Aldrich BC, Molleson L, Nekaris KAI. 2008. Vocalizations as a conservation tool: an auditory survey of the Andean titi monkey Callicebus oenanthe Thomas, 1924 (Mammalia: Primates: Pitheciidae) at Tarangue, Northern Peru. Contributions to Zoology 77:1-6.

Anzenberger G 1988. The Pairbond in the Titi Monkey (Callicebus moloch): Intrinsic versus extrinsic contributions of the pairmates. Folia Primatologica 50:188-203.

Anzenberger G, Mendoza SP, Mason WA. 1986. Comparative studies of social behavior in Callicebus and Saimiri: Behavioral and physiological responses of established pairs to unfamiliar pairs. American Journal of Primatology 11:37-51.

Bicca-Marques JC, Garber PA, Azevedo-Lopes MAO. 2002. Evidence of three resident adult male group members in a species of monogamous primate, the red titi monkey (Callicebus cupreus). Mammalia 66:138-142.

Cäsar C. 2011. Anti-predator behaviour of black-fronted titi monkeys (Callicebus nigrifrons). [PhD 
thesis]. University of Saint Andrews. 216p.

Cäsar C, Byrne RW, Hoppitt W, Young RJ, Zuberbühler K. 2012. Evidence for semantic communication in titi monkey alarm calls. Animal Behaviour 84:405-411.

Cäsar C, Byrne RW, Young RJ, Zuberbühler K. 2012. The alarm call system of wild black-fronted titi monkeys, Callicebus nigrifrons. Behavioural Ecology and Sociobiology 66:653-667.

Cäsar C, Franco ES, Soares GCN, Young RJ. 2008. Observed case of maternal infanticide in a wild group of black-fronted titi monkeys (Callicebus nigrifrons). Primates 49:143-145.

Cäsar C, Zuberbühler K. 2012. Referential alarm calling behaviour in New World primates. Current Zoology 58:680-697.

Cäsar C, Zuberbühler K, Young RJ, Byrne RW. 2013. Titi monkey call sequences vary with predator location and type. Biology Letters 9:20130535.

Caselli CB. 2013. Comportamento territorial de Callicebus nigrifrons Spix, 1823 (Pitheciidae): influência da disponibilidade de frutos e possíveis funções das vocalizações de longo alcance. [PhD thesis]. Campinas: Universidade Estadual de Campinas (UNICAMP).

Caselli CB, Mennill D, Bicca-Marques JC, Setz EZF. 2014. Vocal behavior of black-fronted titi monkeys (Callicebus nigrifrons): Acoustic properties and pehavioral contexts of loud calls. American Journal of Primatology 76:788-800.

Cisneros-Heredia DF, León-Reyes A, Seger S. 2005. Boa constrictor predation on a titi monkey, Callicebus discolor. Neotropical Primates 13:11-12.

Dacier A, de Luna AG, Fernandez-Duque E, Di Fiore A. 2011. Estimating population density of Amazonian titi monkeys (Callicebus discolor) via Playback Point Counts. Biotropica 43:135-140.

de Luna AG, Sanmiguel R, Di Fiore A, Fernandez-Duque E. 2010. Predation and predation attempts on red titi monkeys (Callicebus discolor) and equatorial sakis (Pithecia aequatorialis) in Amazonian Ecuador. Folia Primatologica 81:86-95.

Defler TR. 1983. Some population characteristics of Callicebus torquatus lugens (Humboldt, 1812) (Primates: Cebidae) in Eastern Colombia. Lozania 38:1-9.

DeLuycke AM. 2007. The ecology and behavior of the Rio Mayo titi monkey (Callicebus oenanthe) in the alto Mayo, Northern Peru. [PhD dissertation]. Saint Louis: Washington University. 274p.

Easley SP, Kinzey WG. 1986. Territorial shift in the yellow-handed titi monkey (Callicebus torquatus). American Journal of Primatology 1:307-318.

Felton A, Felton AM, Wallace RB, Gómez H. 2006. Identification, behavioral observations, and notes on the distribution of the titi monkeys Callicebus modestus and Callicebus olallae. Primate Conservation 20:41-46.

Fernandez-Duque E, Di Fiore A, de Luna AG. 2013. Pair-mate relationships and parenting in equatorial saki monkeys (Pithecia aequatorialis) and red titi monkeys (Callicebus discolor) of Ecuador. In: Veiga LM, Barnett AA, Ferrari SF, editors. evolutionary biology and conservation of titis, sakis and uacaris. New York: Cambridge University Press. p 295-302.

Fernandez-Duque E, Valeggia CR, Mason WA. 2000. Effects of pair-bond and social-context on malefemale interactions in captive titi monkeys (Callicebus moloch, Primates: Cebidae). Ethology 106: 1067-1082.

Fragaszy DM. 1980. Comparative studies of squirrel monkeys (Saimiri) and titi monkeys (Callicebus) in travel tasks. Zeitschrift für Tierpsychologie 54:1-36.

Fragaszy DM, Schwarz S, Shimosaka D. 1982. Longitudinal observations of care and development of infant titi monkeys (Callicebus moloch). American Journal of Primatology 2:191-200.

Gestich CC, Caselli CB, Nagy-Reis MB, Setz EZF, da Cunha RGT (2017) Estimating primate population densities: the systematic use of playbacks along transects in population surveys. American 
Journal of Primatology 79: e22586. doi:10.1002/ajp.22586.

Hoffman KA, Mendoza SA, Hennessy MB, Mason WA. 1995. Responses of infant titi monkeys, Callicebus moloch, to removal of one or both parents: Evidence for paternal attachment. Developmental Psychobiology 28:399-407.

Kinzey WG, Robinson JG. 1983. Intergroup loud calls, range size, and spacing in Callicebus torquatus. American Journal of Physical Anthropology 60:539-544.

Kinzey WG, Wright PC. 1982. Grooming behavior in the titi monkey (Callicebus torquatus). American Journal of Primatology 3:267-275.

Kinzey WG, Rosenberger AL, Heisler PS, Prowse DL, Trilling JS. 1977. A preliminary field investigation of the yellow handed titi monkeys, Callicebus torquatus torquatus, in Northern Peru. Primates 18:159-181.

Kinzey WG, Becker M. 1983. Activity pattern of the masked titi monkey, Callicebus personatus. Primates 24:337-343.

Krümberg D, Dingess K. 2013. Seasonal changes in song structure and calling Behaviour of the Bolivian Grey Titi Monkey (Callicebus donacophilus). The 82nd Annual Meeting of the American Association of Physical Anthropologists, Knoxville.

Martínez J, Wallace RB. 2007. Further notes on the distribution of endemic bolivian titi monkeys, Callicebus modestus and Callicebus olallae. Neotropical Primates 14:47-54.

Martínez J, Wallace RB. 2013. New information about the distribution of Callicebus (Pithecidae, Primates) in northern Beni Department, Bolivia. Ecología en Bolivia 48:57-62.

Martinez J, Wallace R B (2016) Ecological and behavioural factors influencing territorial call rates for the Bolivian titi monkeys, Plecturocebus modestus and Plecturocebus olallae. Folia Primatologica 87:279-290

Martins MM, Silva AHP. 1998. Temporal and acoustic properties of long-distance calls of the masked titi monkey, Callicebus personatus. Neotropical Primates 6:46-48.

Melo FR, Mendes SL. 2000. Emission of long calls by groups of Callicebus nigrifrons and their reactions to playbacks. A Primatologia no Brasil 7:215-222.

Meritt DA. 1980. Captive reproduction and husbandry of the Douroucouli aotus trivirgatus and the titi monkey Callicebus spp. International Zoo Yearbook 20:52-59.

Moynihan M. 1966. Communication in the titi monkey, Callicebus. Journal of Zoology 150:77-127.

Moynihan M. 1967. Comparative Aspects of Communication in New World Primates. In: Morris D, editor. Primate Ethology. London: Weidenfeld and Nicolson. p 236-266.

Müller AE, Anzenberger G. 2002. Duetting in the titi monkey Callicebus cupreus: structure, pair specificity and development of duets. Folia Primatologica 73:104-115.

Porras M. 2000. Vocal communication and its relation to activities, social structure, and behavioral context in Callicebus cupreus ornatus. A Primatologia no Brasil 7:265-274.

Ragen BJ, Maningerb N, Mendoza SP, Jarcho MR, Bales KL. 2013. Presence of a pair-mate regulates the behavioral and physiological effects of opioid manipulation in the monogamous titi monkey (Callicebus cupreus). Psychoneuroendocrinology 38:2448-2461.

Ragen BJ, Mendoza SP, Mason WA, Bales KL. 2012. Differences in titi monkey (Callicebus cupreus) social bonds affect arousal, affiliation, and aesponse to reward. American Journal of Primatology 74:758-769.

Robinson JG. 1979. An analysis of the organization of vocal communication in the titi monkey Callicebus moloch. Zeitschrift für Tierpsychologie 49:381-405.

Robinson JG. 1979. Vocal regulation of use of space by groups of titi monkeys Callicebus moloch. Behavioural Ecology and Sociobiology 5:1-15.

Robinson JG. 1981. Vocal Regulation of Inter- and intragroup spacing during boundary encounters in the titi monkey, Callicebus moloch. Primates 22:161-172. 
Rowe N, Martinez W. 2003. Callicebus sightings in Bolivia, Peru and Ecuador. Neotropical Primates 11:32-35.

Sampaio DT, Ferrari SF. 2005. Predation of an infant titi monkey (Callicebus moloch) by a tufted capuchin (Cebus apella). Folia Primatologica 76:113-115.

Souza-Alves JP, Ferrari SF. 2010. Responses of wild titi monkeys, Callicebus coimbrai (Primates: Platyrrhini: Pitheciidae), to the habituation process. Zoologia 27:861-866.

Spence-Aizenberg A. 2010. Affiliative behaviors in pairbonded red titi monkeys (Callicebus discolor). [PhD thesis]. Philadelphia: University of Pennsylvania. $95 \mathrm{p}$.

\section{Chiropotes studies}

Boyle SA, Smith AT. 2010. Behavioral modifications in northern bearded saki monkeys (Chiropotes satanas chiropotes) in forest fragments of central Amazonia. Primates 51:43-51.

Fernandes MEB, 1991. Comunicação social dos cuxiús (Chiropotes satanas uitahicki, Cebidae, Primates). Primatologia do Brasil 3:297-305.

Ferrari SF, Pereira WLA, Santos RR, Veiga LM. 2004. Fatal attack of a Boa constrictor on a bearded saki Chiropotes satanas utahicki. Folia Primatologica 75:111-113.

Lenz BB, Reis AM. 2011. Harpy eagle-primate interactions in the central amazon. The Wilson Journal of Ornithology 123:404-408.

Silva SSB, Ferrari SF. 2008. Behavior patterns of southern bearded sakis Chiropotes satanas in the fragmented landscape of eastern Brazilian Amazonia. American Journal of Primatology 70:1-7.

van Roosmalen MGM, Mittermeier RA, Fleagle JG. 1988. Diet of the nothern bearded saki (Chiropotes satanus chiropotes): a neotropical seed predator. American journal of Primatology 14:1115.

\section{Pithecia studies}

Adams DB. 2009. A Preliminary study on vocal communication in the Gray's bald-faced saki monkey, Pithecia irrorata. [M.A. Thesis]. San Marcos: Texas State University. 146 p.

Buchanan DB, Mittermeier RA, van Roosmalen MGM. 1981. The saki monkeys, genus Pithecia. In: Coimbra filho AF, Mittermeier RA, editors. Ecology and behaviour of neotropical primates. Rio de Janeiro: Academia Brasileira de Ciências. p 391-417.

Di Fiore A, Fernandez-Duque E, Hurst D. 2007. Adult male replacement in socially monogamous equatorial saki monkeys (Pithecia aequatorialis). Folia primatologica 78: 88-98.

Fernandez-Duque E, Di Fiore A, de Luna AG, Primates P. 2013. Pair-mate relationships and parenting in ecuatorial saki monkeys (Pithecia aequatorialis) and red titi monkeys (Callicebus discolor) of Ecuador. In: Veiga LM, Barnett AB, Ferrari SF, Norconk MA, editors. Evolutionary biology and conservation of titis, sakis and uacaris. Cambridge: Cambridge University Press. p 295-302.

Fitch WTS. 1994. Vocal Tract Length Perception and the Evolution of Language. [PhD thesis]. Providence: Brown University. 95 p.

Henline WT. 2007. Vocal repertoire of white-faced sakis (Pithecia pithecia). [MSc dissertation]. Richmond (USA): Eastern Kentucky University. 49 p.

Luna AG, Sanmiguel R, Di Fiore A, Fernandez-Duque E. 2010. Predation and predation attempts on red titi monkeys (Callicebus discolor) and equatorial sakis (Pithecia aequatorialis) in Amazonian Ecuador. Folia Primatologica 81:86-95.

Norkonk M. 2006. Long-term study of group dynamics and female reproduction in venezuelan Pithecia pithecia. International Journal of Primatology 27:653-674. 
Norkonk MA. 2011. Sakis, uakaris and titi monkeys: Behavioral diversity in a radiation of primate seed predators. In: Campbell CJ, Fuentes A, MacKinnon KC, Bearder SK, Stumpf RM, editors. Primates in perspective. New York: New York University Press. p 122-139.

Rosemberg AL, Norkonk MA, Garber PA. 1997. New perspectives on the pitheciines. In: Norkonk MA, Rosemberg AL, Garber PA, editors. Adaptative radiations on Neotropical primates. New York: Plenum press. p. 329-334. 